\title{
Applications of FEM in Condition Monitoring of Transformer Clamping System
}

\author{
Lakshitha Naranpanawe, Student Member, IEEE, \\ School of Information Technology and Electrical Engineering, \\ The University of Queensland, Brisbane, \\ Australia, \\ w.naranpanawe@uq.edu.au,
}

\begin{abstract}
Power transformer condition monitoring is an important topic in both research and practice. However, condition monitoring of power transformer winding clamping system is rarely discussed. As a result, no reliable condition monitoring technique has been developed to assess the condition of power transformer winding clamping system. However, Finite Element Modelling (FEM) based simulations can be utilised to understand the complex behaviour of winding clamping structure under different operating conditions and then acquired knowledge can be used to improve the accuracy of existing condition monitoring techniques. Therefore, this study reviews the research status in use of FEM based simulations in condition monitoring and diagnosis of power transformer winding clamping system.
\end{abstract}

Keywords - Finite Element Modelling; power transformers; condition monitoring; mechanical system

\section{INTRODUCTION}

Even a short unexpected outage or unscheduled maintenance in a power transformer could lead to an interruption in power supply. Therefore, condition monitoring of power transformer is a topic with utmost importance and timely value. However, being a complex system with highly dynamic operating conditions accurate condition estimation and fault diagnosis of power transformers is challenging. Further, transformer is a complex system composed of an insulation system and a mechanical system. The condition monitoring of the insulation system is a well-established and widely discussed topic. However, surprisingly condition monitoring of the mechanical system, especially the clamping system is a rarely discussed.

Clamping structure provide the short circuit ride through capability of power transformers by absorbing the heavy electromagnetic forces during high current fault conditions [1]. With the ageing of winding clamping system power transformers become vulnerable to high current faults as a result of progressive loss of winding clamping pressure [2, 3]. Tilting of conductors, axial collapse due to conductor "telescoping", axial bending, radial bending, spiralling are the most common failure modes due to strong electromagnetic forces in loosely clamped windings [4-6]. Main reason for loss of clamping pressure with ageing is the degradation of mechanical properties of high-density pressboard parts in the winding structure [2]. Therefore, detailed knowledge of the mechanical properties of pressboard is critical for understanding the behaviour of transformer winding clamping structure under different operating conditions.

\author{
Chandima Ekanayake, Senior Member IEEE, \\ Griffith School of Engineering, Gold Coast Campus, Griffith \\ University, Gold Coast, \\ Australia \\ c.ekanayake@griffith.uq.edu.au
}

Even though the clamping system of a power transformer winding is critical for its reliable operation, it was found that no direct clamping pressure monitoring system has been developed yet. However, to overcome this problem, many researchers have developed on-load transformer tank vibration monitoring based techniques to estimate the health of power transformer winding clamping systems [7-10]. Nevertheless, due to the lack of understanding of the dynamic behaviour of winding clamping pressure, none of the existing techniques is reliable $[11,12]$. Moreover, use of laboratory investigations to improve the accuracy of vibration based clamping pressure estimation techniques is also difficult because of the complex winding construction and dynamic operating conditions.

Finite Element Modelling (FEM) is being widely used by transformer manufacturers during the design stage to study the magnetic flux distribution, losses, and structural health [1316]. However, existing literature state that FEM simulations can be used not only during manufacturing process but also to understand the behaviour of field installed transformers [12]. Simulating the magnetic flux distribution and performance of core clamps and joints $[13,14]$, temperature distribution $[17$, 18] and thermally driven moisture distribution inside the transformer $[19,20]$ are some examples. Further, Badgujar et al [21] have used FEM to model law-frequency response of a transformer winding. Yuan et al [22] have shown that frequency domain spectroscopy (FDS) results of oil-paper system of power transformer can be modelled using FEM.

Therefore, it is possible to utilise FEM bases simulations combined with laboratory investigations to study and understand the complex behaviour of power transformer winding clamping systems $[12,23]$. In this approach, first, behaviour of mechanical properties of pressboard under different operating conditions can be studied using laboratory investigations. Secondly, experimental data can be used in FEM simulations of power transformer winding structure to understand the behaviour of clamping systems of real transformer windings [12, 23-25].

\section{FEM SIMULATION METHOD}

As described before, due to the complexity of the power transformer winding structure and the dynamic operating conditions, use of laboratory experiments to understand the behaviour of power transformer winding clamping system is practically impossible. However, laboratory experiments can be combined with FEM simulations to study such complex system effectively $[11,12,23]$. In this approach, first 
mechanical properties of transformer solid insulation materials can be measured under different operating conditions. Then the results of laboratory investigations can be used in a FEM simulation of real power transformer winding structure.

Such FEM based simulation method has three major parts i.e. pre-processing, solving, and post processing. In the preprocessing stage, a CAD model is required to be generated. After importing the CAD model into the FEM software, material properties have to be defined. Then, it is essential to apply the correct boundary conditions in FEM to get accurate results. After the pre-processing, FEM simulation can be solved to calculate electromagnetic forces in the transformer winding structure. Then the mechanical stress distribution in the winding due to electromagnetic forces and clamping forces can be calculated. After calculating the mechanical stresses, modal parameters of the winding structure can be computed to study the vibration behaviour of power transformer winding structure. Finally, above process can be repeated for different operating conditions by changing the temperature, moisture level, ageing level, and winding

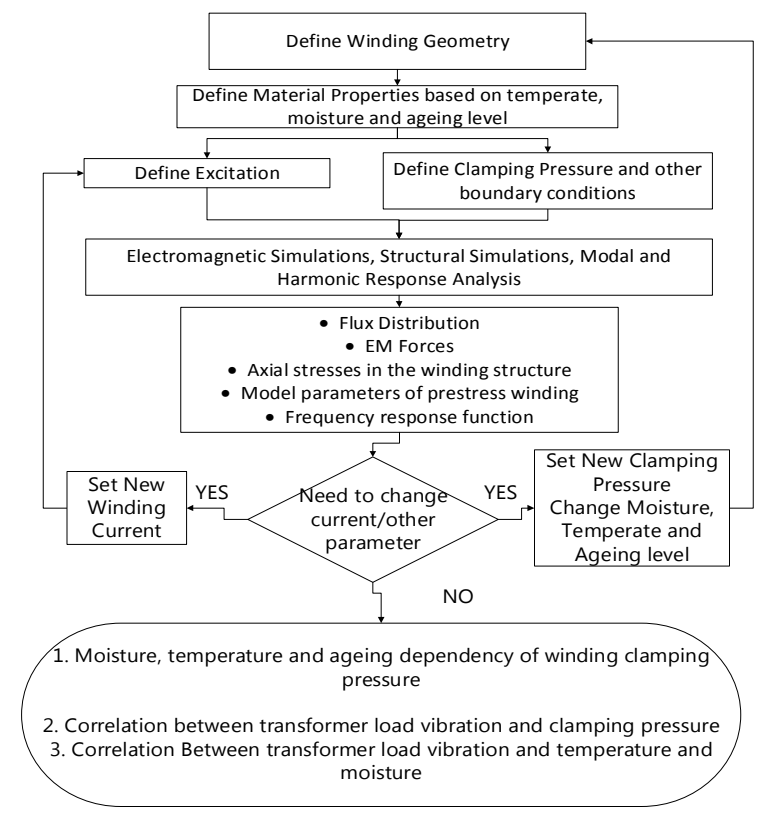

Fig. 1. Possible finitel element simulation procedure for improve the accuracy of existing clamping pressure estemation techneques

clamping pressure. Fig. 1 illustrates a detailed diagram of the simulation method described above.

In order to explain the proposed simulation procedure, FEM simulations of a $10.5 / 0.4 \mathrm{kV}, 100 \mathrm{kVA}$, three-phase disc type test transformer winding shown in Fig. 2 were used. Technical specifications of the winding are listed in Table 1. On the other hand, during laboratory investigations, compressive stress-strain curves, hygroscopic swelling, and residual strain after a compression cycle of high-density pressboard samples were measured at different moisture,

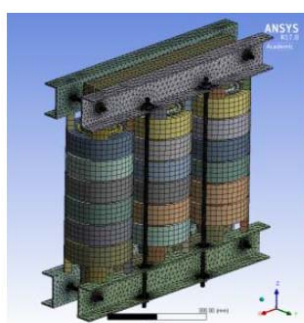

(a)

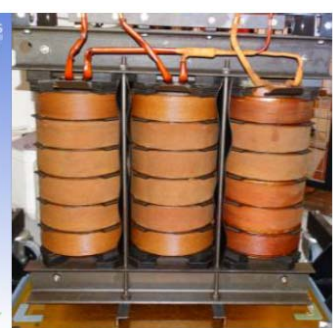

(b)
Fig. 2. 10.5/0.4 kV, $400 \mathrm{kVA}$ step-down distribution transformer (a) -

3D model, (b) - actual transformer

temperature and ageing levels. Further, ANSYS was used for FEM based simulations.

TABLE 1 TECHNICAL SPECIFICATIONS OF A $10.5 \mathrm{KV} / 400 \mathrm{~V}$ TRANSFORMER WINDING

\begin{tabular}{|c|c|}
\hline Specifications & Outer Winding \\
\hline Voltage (V) & 10500 \\
\hline Nominal Current (A) & 5.5 \\
\hline Number of Discs & 6 \\
\hline Total number of turns & 2580 \\
\hline Outer diameter $(\mathrm{mm})$ & 206 \\
\hline Inner diameter (mm) & 164 \\
\hline Height of a disc $(\mathrm{mm})$ & 65 \\
\hline Total Winding Height (mm) & 520 \\
\hline
\end{tabular}

\section{CAD Model AND the Material Properties}

\section{A. CAD Model of the transformer winding structure}

Because of the complex nature of power transformer winding structure, simplified winding geometry has to be used. If a 3D geometry with all the details of a real transformer winding is used in FEM simulations, required computational power will be unnecessarily high. As a result, meshing will be complex and simulation results will be poorly converged. Therefore, it is required to simplify the geometry without affecting the accuracy of the simulation results.

Reference [24] describes the assumptions that can be used to simplify the 3D CAD model of the transformer winding. According to [24], first step is to measure all required dimensions of the actual transformer winding. Then, instead of modelling individual copper conductors in each disc, they can be modelled as a single copper disc that has the same copper cross section area. Further, insulation parts i.e. key spacers, clamping rings etc. that made up of several layers of thin pressboard parts can be modelled as single pressboard blocks avoiding unnecessary contact surfaces.

\section{B. Material Properties}

High-density pressboard, copper, and steel are the main materials that are used to create the power transformer winding structure. Among them, copper and steel can be easily modelled in FEM simulations using their density, modulus of elasticity and Poisson's ratio (see Table 2). However, high-density pressboard has a highly nonlinear outof-plane compression behaviour [26] as shown in Fig. 3 . Moreover, pressboard is a highly hygroscopic material [25]. In other words, both thickness and out of plane compressive behaviour of pressboard parts are moisture dependent. Further, 
as shown in Table 3 and Fig. 3 (top), with increasing moisture content, thickness of pressboard shows an increasing trend while its compressibility shows a decreasing trend [25].

TABLE II MATERIALS AND RELATED MECHANICAL PROPERTIES USED IN FEM

\begin{tabular}{|c|c|c|c|c|}
\hline Material & Part & $\begin{array}{c}\text { Density } \\
\text { (Kgm }^{-3} \text { ) }\end{array}$ & $\begin{array}{c}\text { ME } \\
(\mathbf{G P a})\end{array}$ & PR \\
\hline Pressboard & $\begin{array}{c}\text { Spacers, } \\
\text { radial } \\
\text { supports and } \\
\text { Insulating } \\
\text { blocks }\end{array}$ & 1140 & - & 0.33 \\
\hline Copper & Windings & 8900 & 100 & 0.35 \\
\hline Steel & $\begin{array}{c}\text { Core, } \\
\text { clamping } \\
\text { beams and tie } \\
\text { rods }\end{array}$ & 8000 & 115 & 0.29 \\
\hline
\end{tabular}

TABLE III VARIATION OF PRESSBOARD THICKNESS AND COMPRESSIVE MODULUS WITH MOISTURE CONTENT

\begin{tabular}{|c|c|}
\hline & Clamping Pressure (MPa) \\
\hline Moisture content & Change in thickness \% \\
\hline $0.5 \%$ & 0 \\
\hline $4 \%$ & 3.4 \\
\hline $9 \%$ & 6.9 \\
\hline
\end{tabular}

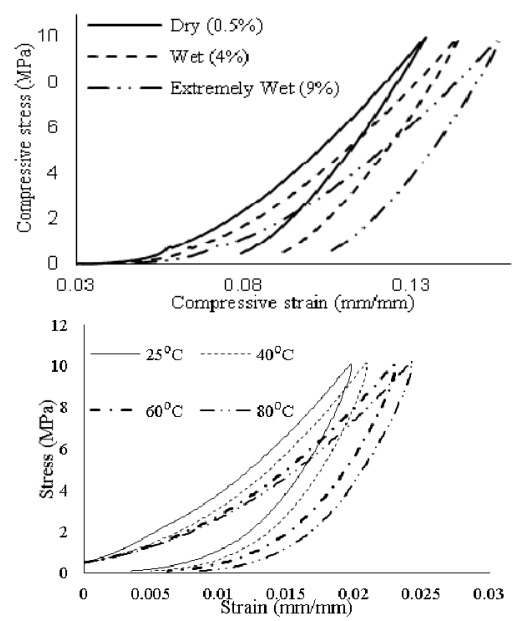

Fig. 3. Moisture (top) and Temperature (bottom) dependancy of pressboard compressive stress-strain curve

On the other hand, mechanical properties of pressboard are not only moisture dependent but also temperature dependent [12]. Similar to any other material, with increasing temperature thickness of pressboard parts will increase because of the thermal expansion. Moreover, from the compressive stress-strain curves of pressboard shown in Fig.3 (bottom) it can be clearly seen that thermal softening occurs with increasing temperature. Therefore, it is essential to use a material model in FEM tool that can simulate the complex compression characteristics of pressboard [25].

Several detailed material models for pressboard can be found in existing literature [26, 27]. However, those material models have been developed to cater the requirements of pressboard manufacturers. Therefore, they are extremely complex and difficult to programme into commercial FEM tools when studying complex geometrical structure. However, according to $[23,25]$ gasket material model can be successfully used to simulate the out of plan compression behaviour of pressboard parts in power transformer winding structure. Further, this gasket material model can be easily characterised using the experimental compressive stress-strain data. Therefore, using the compressive stress-strain curves of pressboard measured under different moisture, temperature and ageing levels, effect of moisture, temperature and ageing on power transformer winding clamping pressure can be simulated $[12,25]$.

\section{FEM SIMULATIONS}

As shown in Fig.1, FEM based winding clamping system simulation procedure discussed in this paper is has three types of FEM simulations namely electromagnetic, structural and modal/harmonic response analysis.

\section{A. Electromagnetic Simulations}

Electromagnetic simulations were used to calculate the leakage flux distribution in the winding system. After computing leakage flux distribution, the results of electromagnetic simulations were post processed to calculate the electromagnetic forces excreted on the winding conductors. In order to solve the magnetostatic problem using FE method, Maxwell's equation shown in (1) is solved to calculate the magnetic field intensity by the 3D magnetostatic solver of the FEM tool.

$$
\nabla \times \vec{H}=\vec{J}
$$

Here, $\vec{H}$ is the magnetic field intensity and $\vec{J}$ is the current density vector, which is defined by the user. After calculating $\vec{H}$, (2) is used to calculate the magnetic flux density $\vec{B}$.

$$
B=\mu_{0} \mu_{r} H
$$

After calculating $B$, Gauss's law for magnetism i.e. (3) is used for the error evaluation.

$$
\nabla \cdot \vec{B}=0
$$

If the solution obtained after certain iteration is correct, according to (3) divergence of magnetic flux density $(\vec{B})$ is zero. However, the initial mesh used by the magnetostatic solver is not refined hence typically the initial solution is erroneous as shown in (4).

$$
\nabla \bullet \vec{B}_{\text {solution }}=\text { error }
$$

Therefore, solver refines the mesh as specified by the user in the next iteration and a new set of $\vec{B}$ values are calculated. After each iteration, (4) is used to calculate the error and repeat above process until the error reach the error margin specified by the user. 


\section{B. Coupled Electromagnetic-Structural Analysis, Modal Analysis, and Harmonic Response Analysis}

After calculating the leakage flux distribution and electromagnetic forces in the winding structure, static structural analysis can be used to calculate the stress distribution of the transformer winding under clamping force and electromagnetic forces. Then, as the next step, FEM simulations can be used to understand the mechanical vibration characteristics of power transformer winding structure.

In a disc, type transformer winding, conductors are more likely to oscillate in axial direction under electromagnetic forces [28, 29]. Further, according to Lorentz force law, electromagnetic forces are equal to the volume integral of the cross product between current density vector $(J)$ and Magnetic flux density vector $(B)$ as shown in (5).

$$
\vec{F}=\int_{V} \vec{J} \times \vec{B}
$$

Further, because both $J$ and $B$ are proportional to winding current, magnitude of the electromagnetic forces are proportional to the square of the winding current and have a fundamental frequency of twice the frequency of winding current. Thus, in a $50 \mathrm{~Hz}$ system, fundamental frequency of electromagnetic forces is $100 \mathrm{~Hz}$. Therefore, under both normal and faulty operating conditions, power transformer winding tend to vibrate axially with a fundamental frequency of $100 \mathrm{~Hz}$ [30].

Being a complex structure with large number of degree of freedoms, power transformer winding has large number of natural frequencies. These natural frequencies and other modal parameters (mode shapes and damping ratios) decide the vibration characteristics of the transformer winding structure [24]. Therefore, any external factor that could change the modal parameters of the winding structure influences the vibration pattern. Therefore by calculating the modal parameters, mainly natural frequencies, under different operating conditions, it is possible to understand the dynamic behaviour of the mechanical vibration characteristics of the winding structure.

\section{Post Processing AND INTERPRETATION OF FEM BASED SiMULATION RESULTS}

\section{A. Axial Stress Distribution of the Winding Structure and Electromagnetic Forces}

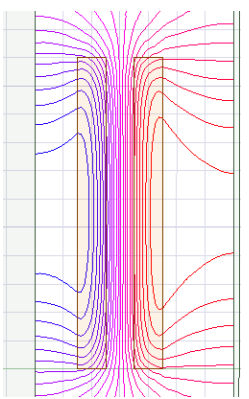

Fig.4 2D leakage flux pattern of a transformer with two concentric windings
Fig. 4 shows the leakage flux lines in the transformer winding structure computed using magnetostatic FEM simulation. According to the figure, it is clear that radial flux component is dominant at the top and bottom ends of the winding while it is negligible in the middle of the winding. On the other hand, axial leakage flux is significant in the middle part and negligible at the ends. Moreover, according to (5), directions of the EM forces are perpendicular to the direction of both leakage flux and current density vector. Therefore, top

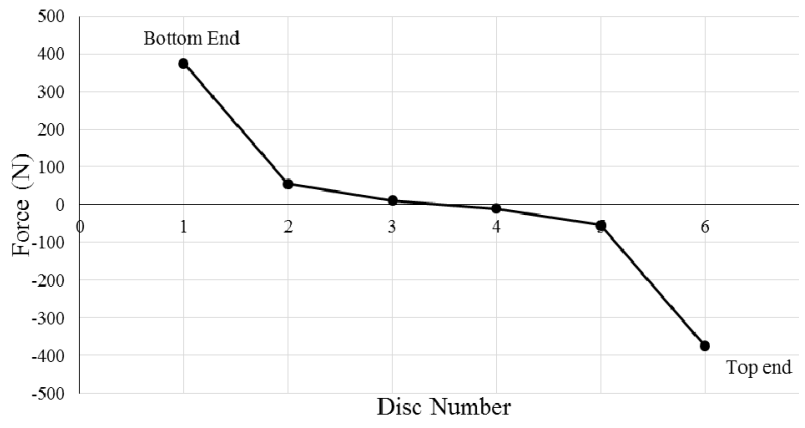

Fig. 5 Axial forces on winding discs of a 100kVA 10/0.4kV test transformer during a high current fault (10 times the normal current)

and bottom ends of the winding structure experience strong axial forces while middle part of the winding experience strong radial forces.

Fig. 5 shows the magnitude of the axial forces on the outer winding discs of the $100 \mathrm{kVA}, 10 / 0.4 \mathrm{kV}$ transformer under a fault current of ten times of its nominal current. From the figure, it can be clearly seen that as expected, axial forces are dominant at the two ends of the winding. Further, as the directions of the axial forces in the top half and the bottom half of the winding are opposite to each other, they tend to

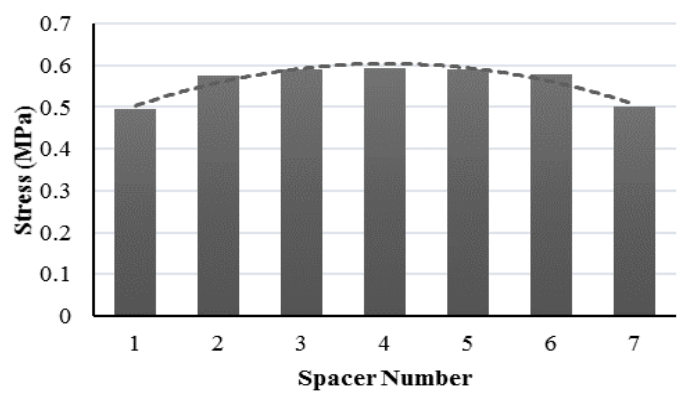

Fig. 6 Axial stresses on the disc spacers under an initial clamping pressure of $0.5 \mathrm{MPa}$ and axial EM forces shown in Fig. 6

compress the winding structure axially.

After computing the electromagnetic forces, they can be imported into a structural simulation to calculate the axial stress distribution in the winding structure. Fig. 6 illustrates the axial stress on the disc spacers of the winding structure. From the figure, it can be seen that even though highest axial forces are acting on the conductors closer to the top and bottom ends of the winding, as result of the cumulative addition of axial forces on each disc, pressboard parts in the middle of the winding experience the highest compressive stresses. Therefore, it can be predicted that, during a high current fault, pressboard parts in the middle of the winding experience the highest compressive stress. 
B. Moisture and Temperature Dependany of Winding Clamping Pressure

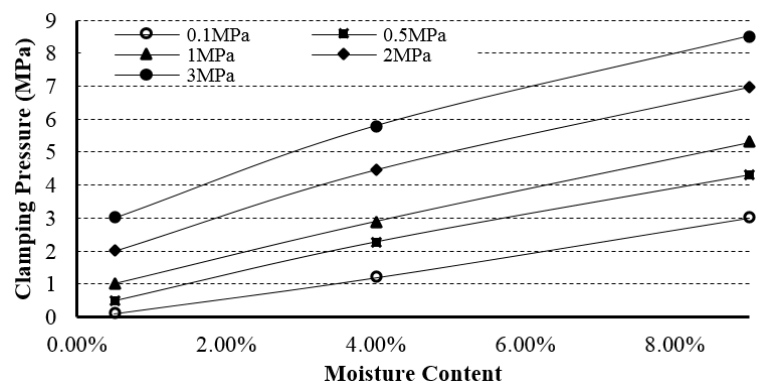

Fig. 7 Change in winding clamping pressure with increasing moisture content different initial clamping pressure levels [25]

After computing the axial stress distribution of the transformer winding, experimental compressive stress-strain data, hygroscopic swelling, and thermal expansion data of pressboard can be used in FEM simulations to understand the moisture and temperature dependency of power transformer winding clamping pressure. Fig. 7 shows the changes in winding clamping pressure of the test transformer winding with increasing moisture content. From the figure it can be seen that the combined effect of softening and hygroscopic swelling tend to increase the winding clamping pressure with increasing moisture content (See Fig. 7).

TABLE IV TEMPERATURE DEPENDANCY OF WINDING CLAMPING PRESSURE OF A $10 \mathrm{KV} / 0.4 \mathrm{KV}, 100 \mathrm{VA}$ WINDING

\begin{tabular}{|c|c|}
\hline & Clamping Pressure (MPa) \\
\hline $20^{\circ} \mathrm{C}$ & 1 (initial) \\
\hline $50^{\circ} \mathrm{C}$ & 2.6 \\
\hline $80^{\circ} \mathrm{C}$ & 3.6 \\
\hline
\end{tabular}

Same procedure that used to simulate the effect of moisture on winding clamping pressure can be used to simulate the temperature dependency of winding clamping pressure. In this case, thermal expansion coefficient and compressive stress strain curves of pressboard measured under different temperature levels can be used in the structural simulations. From the results listed in Table IV, it is clear that combined effect of thermal expansion and thermal softening tend to increase the clamping pressure with increasing temperature.

\section{Mechanical Vibration Characteristics of Transformer Winding Structure.}

After the structural simulations, modal parameters of the pre-stressed winding can be calculated using the FEM simulations. Reference [24] present a comparison between modal parameters of the simplified winding geometry and the actual transformer winding (See Table V). From the natural frequencies listed in Table $\mathrm{V}$, it can be clearly seen that simulated and measured natural frequencies of the transformer winding structure are in a good agreement. In another words, data listed in Table V confirms that simplified CAD model and the FEM simulation method is capable of
TABLE V . COMPARISON BETWEEN MEASURED AND SIMULATED NATURAL FREQUENCIES OF THE $100 \mathrm{KVA}$ 10/0.4KV TEST TRANSFORMER WINDING [26].

\begin{tabular}{|c|c|c|c|}
\hline & \multicolumn{3}{|c|}{ Natural Frequency (Hz) } \\
\hline Mode & FEM & EMA & Error (\%) \\
\hline 1 & 56.612 & 48.83 & -13.74 \\
\hline 2 & 58.34 & 63.48 & 8.80 \\
\hline 3 & 70.99 & 70.80 & -0.27 \\
\hline 4 & 72.95 & - & 100 \\
\hline 5 & 73.61 & - & 100 \\
\hline 6 & 79.08 & 83.01 & 4.95 \\
\hline 7 & 115.02 & 113.53 & -1.29 \\
\hline 8 & 121.18 & 118.41 & -2.28 \\
\hline 9 & 122.96 & 122.07 & -0.72 \\
\hline 10 & 134.08 & & -0.76 \\
\hline 11 & 134.38 & 133.06 & -0.98 \\
\cline { 1 - 1 } 12 & 134.85 & & -1.33 \\
\hline 13 & 145.34 & 145.26 & -0.05 \\
\hline 14 & 188.46 & 187.99 & -0.25 \\
\hline 15 & 373.81 & & -2.03 \\
\hline 16 & 373.97 & 366.21 & -2.07 \\
\hline 17 & 374.03 & \multirow{2}{*}{394.29} & 5.41 \\
\hline 18 & 589.43 & 598.14 & 1.47 \\
\hline
\end{tabular}

calculating the modal parameters of the real test transformer winding.

Finally, after model validation, simplified CAD model with the measured mechanical properties of pressboard can be used to study the changes in on load vibration patterns of the power transformer winding with changing winding clamping pressure. Fig. 8 illustrates the simulated frequency response functions of the test transformer winding under different initial clamping pressure levels. From the figure, it is clear that on load mechanical vibration characteristics of power transformer winding structure is sensitive to the changes in winding clamping pressure. Therefore, it is possible to use on-load tank vibration signals of a power

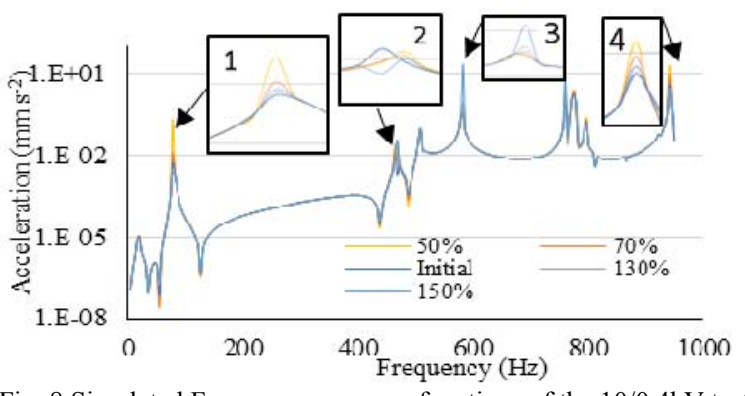

Fig. 8 Simulated Frequency response functions of the $10 / 0.4 \mathrm{kV}$ test transformer winding under different clamping pressure levels [26] 
transformer can be used to detect the loose winding conditions of power transformers.

\section{CONCLUSIONS}

This paper presents a detailed review on use of FEM in power transformer condition monitoring applications. From existing literature, it was found that FEM simulations can be utilised to understand the moisture, temperature and ageing dependent changes in both power transformer winding clamping pressure and mechanical vibration characteristics. After that, acquired knowledge can be used to improve the accuracy of existing condition monitoring techniques used to assess the condition of power transformer winding clamping structure.

\section{ACKNOWLEDGMENT}

The authors would like to thank the Australian Research Council (ARC) and industry partners AusGrid, Ergon Energy, Powerlink Queensland, TransGrid and Wilson transformer for the financial and in-kind support.

\section{REFERENCES}

[1] S. A. K. S.V. Kulkarni, "Short-Circuit Stresses and Strength," in Design, Technology, and Diagnostics, Second Edition, ed: CRC Press, 2012, pp. 243-298.

[2] C. K. T. Prevost, D. Woodcock, "The effects on winding clamping pressure due to change in moisture, temperature and insulation age," presented at the 67th annual international conference of Doble clients, 2000.

[3] A. M. Andrei Marinescu "About Axial Clamping Force Monitoring at Power Transformer Windings during their Active Lifetime," presented at the Annals of the University of Craiova, , 2008.

[4] G. Bertagnolli, The ABB approach to short-circuit duty of power transformers, 2007.

[5] A. Bakshi and S. V. Kulkarni, "Coupled Electromagnetic-Structural Analysis of the Spiraling Phenomenon in a Helical Winding of a Power Transformer," Power Delivery, IEEE Transactions on, vol. 29, pp. 235-240, 2014.

[6] A. Bakshi and S. V. Kulkarni, "Analysis of Buckling Strength of Inner Windings in Transformers Under Radial Short-Circuit Forces," Power Delivery, IEEE Transactions on, vol. 29, pp. 241245, 2014.

[7] Z. Berler, A. Golubev, V. Rusov, V. Tsvetkov, and C. Patterson, "Vibro-acoustic method of transformer clamping pressure monitoring," in IEEE Conference Record of Ieee International Symposium On Electrical Insulation, 2000, pp. 263-266.

[8] X. Poan, Z. Zhishu, M. Macalpine, J. Zhijian, and R. Zhushi, "Estimation of the Clamping Pressures of Transformer Windings from Vibration Measurements," HKIE Transactions, vol. 15, pp. 3035, 2008/01/01 2008.

[9] T.-T. He, J.-D. Wang, J. Guo, H. Huang, X.-x. Chen, and J. Pan, "A Vibration Based Condition Monitoring System for Power Transformers," in Power and Energy Engineering Conference, 2009. APPEEC 2009. Asia-Pacific, 2009, pp. 1-4.

[10] L. Hongkui, L. Yan, and Y. Xiaohui, "Axial vibrations modal analysis and computation of power transformer windings under different levels of pre-compression," in Applied Superconductivity and Electromagnetic Devices, 2009. ASEMD 2009. International Conference on, 2009, pp. 229-232.

[11] W. M. L. B. Naranpanawe, K. M. K. S. Bandara, T. K. Saha, C. Ekanayake, and P. K. Annamalai, "Effect of pressboard ageing on power transformer mechanical vibration characteristics," in Power and Energy Engineering Conference (APPEEC), 2015 IEEE PES Asia-Pacific, 2015, pp. 1-5.

[12] L. Naranpanawe, T. Saha, and C. Ekanayake, "Moisture and temperature effects on power transformer winding clamping pressure," in 2016 IEEE PES Asia-Pacific Power and Energy Engineering Conference (APPEEC), 2016, pp. 74-78.

[13] M. Chiampi, A. Negro, and M. Tartaglia, "A finite element method to compute three-dimensional magnetic field distribution in transformer cores," IEEE Transactions on Magnetics, vol. 16, pp. 1413-1419, 1980.

[14] T. Nakata, N. Takahashi, and Y. Kawase, "Magnetic performance of step-lap joints in distribution transformer cores," IEEE Transactions on Magnetics, vol. 18, pp. 1055-1057, 1982.

[15] M. Okabe, M. Okada, and H. Tsuchiya, "Effects of magnetic characteristics of materials on the iron loss in the three phase transformer core," IEEE Transactions on Magnetics, vol. 19, pp. 2192-2194, 1983.

[16] T. H. Fawzi and A. A. Elkhalek, "New approaches for the applications of FEM in the routine design of power transformers using PC's," in CIRED 2005 - 18th International Conference and Exhibition on Electricity Distribution, 2005, pp. 1-5.

[17] A. Elmoudi, M. Lehtonen, and H. Nordman, "Thermal model for power transformers dynamic loading," in Conference Record of the 2006 IEEE International Symposium on Electrical Insulation, 2006, pp. 214-217.

[18] L. Yan, L. Longnv, J. Yongteng, L. Shuangpeng, and Z. Fengge, "Calculation and analysis of hot-spot temperature-rise of transformer structure parts based on magnetic-thermal coupling method," in 2013 International Conference on Electrical Machines and Systems (ICEMS), 2013, pp. 2259-2262.

[19] Y. Cui, H. Ma, T. Saha, C. Ekanayake, and G. Wu, "Multi-physics modelling approach for investigation of moisture dynamics in power transformers," IET Generation, Transmission \& Distribution, vol. 10, pp. 1993-2001, 2016.

[20] Y. Cui, H. Ma, T. Saha, C. Ekanayake, and D. Martin, "MoistureDependent Thermal Modelling of Power Transformer," IEEE Transactions on Power Delivery, vol. 31, pp. 2140-2150, 2016.

[21] K. P. Badgujar, A. P. S. Baghel, and S. V. Kulkarni, "A coupled field-circuit formulation and a duality based approach for analysis of low-frequency response of transformers," in 2013 Annual IEEE India Conference (INDICON), 2013, pp. 1-6.

[22] L. Yuan, Y. Jing-gang, G. Shan, and L. Hong-tao, "Simulation analysis on FDS of power transformer by FEM approach," in 2016 IEEE International Conference on High Voltage Engineering and Application (ICHVE), 2016, pp. 1-4.

[23] C. E. Lakshitha Naranpanawe, Tapan Saha, "Finite Element Analysis to Understand the Mechanical Defects in Power Transformer Winding Clamping Structure," presented at the IEEE Power and Energy Systems General Meeting 2017 accepted to be published.

[24] L. Naranpanawe and C. Ekanayake, "Finite element modelling of a transformer winding for vibration analysis," in 2016 Australasian Universities Power Engineering Conference (AUPEC), 2016, pp. 16.

[25] L Naranpanawe, C. Ekanayake, T Saha, P Annamalei, "Influence of Moisture Dependency of Pressboard on Transformer Winding Clamping Pressure," IEEE Transaction of Dielectric and Electric Insulation to be published, 2017.

[26] D. D. Tjahjanto, O. Girlanda, and S. Östlund, "Anisotropic viscoelastic-viscoplastic continuum model for high-density cellulose-based materials," Journal of the Mechanics and Physics of Solids, vol. 84, pp. 1-20, 11// 2015.

[27] M. Nygards, "Modelling the out-of-plane behaviour of paperboard," Nordic pulp and paper research journal, vol. Vol 24, pp. 72-76, 2009.

[28] L. Yan, Z. Wei, J. Yongteng, and S. Xin, "Axial vibration analysis of power transformer active part under short-circuit," in Electrical Machines and Systems (ICEMS), 2011 International Conference on, 2011, pp. 1-4.

[29] Y. Hori and K. Okuyama, "Axial Vibration Analysis of Transformer Windings Under Short Circuit Conditions," Power Apparatus and Systems, IEEE Transactions on, vol. PAS-99, pp. 443-451, 1980.

[30] H. Kaixing, H. Hai, Z. Jing, Z. Jianping, Z. Yangyang, and L. Jiangming, "Time-frequency analysis for power transformer fault detection using vibration method," in 2014 9th IEEE Conference on Industrial Electronics and Applications, 2014, pp. 2110-2114. 